\title{
Determining the Influences of a Hidden Curriculum on Students' Character Development Using the Illuminative Evaluation Model
}

\author{
Melanie Joy Gunio*
}

* College of Education, University of the Philippines, Diliman, Quezon City, Philippines

Email: mdgunio1@up.edu.ph

\section{Article Info}

Received: October 14, 2020

Revised: July 12, 2021

Accepted: July 27, 2021

\section{$10.46303 /$ jcsr.2021.11}

\section{How to cite}

Gunio, M. J. (2021). Determining the Influences of a Hidden Curriculum on Students' Character Development Using the Illuminative Evaluation Model. Journal of Curriculum Studies Research, 3(2), 194-206 https://doi.org/10.46303/jcsr.2021.11

\section{Copyright license}

This is an Open Access article distributed under the terms of the Creative Commons Attribution 4.0 International license.

https://creativecommons.org/licenses/by/4.0/

\section{ABSTRACT}

This study aimed to determine whether the Illuminative Evaluation Model, with its three-stage framework: Investigate, Inquire Further, and Explain, can be used as a methodology in understanding the influences of a hidden curriculum on the character development of pre-elementary students. In Stage 1 Investigate, document analysis, observations, and interviews were conducted to examine the characteristics which were targeted to be developed through the formal curriculum, and the deviations and unintended outcomes that occurred during implementation. In Stage 2 Inquire Further, surveys, structured observations, and focus group discussions were conducted to progressively focus on selected issues. In Stage 3 Explain, principles and patterns were organized to describe the hidden curriculum. In conclusion, the Illuminative Evaluation Model was found to be effective as a tool in determining the influences of a hidden curriculum on students' character development.

\section{KEYWORDS}

Curriculum evaluation; Illuminative Evaluation Model; hidden curriculum; qualitative evaluation; character development 


\section{INTRODUCTION}

Conventional approaches to curriculum evaluation are often within the paradigm of the experimental and psychometric traditions wherein objective methods are more prominent (Parlett \& Hamilton, 1972). This has led to evaluation results which are often restricted in scope due to these approaches' failure to account for the subtler aspects of curriculum implementation, one of which is the hidden curriculum.

This study intends to inquire whether the instructional evaluation model developed by Malcolm Parlett and David Hamilton (1972) named Illuminative Evaluation Model (IEM), which stands within the alternative anthropological paradigm, can be used to determine the influences of the hidden curriculum on students' character development. Under this paradigm, this study intends to provide a complete picture of the educational program (Madaus et al., 1983; Ornstein \& Hunkins, 1993).

The hidden curriculum is a commonly neglected component of curriculum given its implicit nature. Whereas the formal or intended curriculum is characterized by planned experiences and activities that students undertake in their educational program, the hidden curriculum describes the unintended and implicit learning derived by students through socialization with other people which leads to the internalization of values, attitudes, behaviors and skills (Elliot et al., 2016). It is significant for it reveals aspects of schooling that provide elements of socialization that may not be a part of the intended curriculum. The hidden curriculum, therefore, conditions the norms, values, and belief systems which in turn shapes students' character development as they deal with school life (Glatthorn et al., 2009; Margolis, 2001; Tallerico, 2012).

The hidden curriculum is originally conceived as a negative mechanism inherent in schools due to associated concepts of power, control, discipline, and punishment which have been used to fuel socio-economic interests of capitalism (Halpern, 2018). This negative connotation and its imprecise nature are generally the reasons why greater attention was given to the intended curriculum in the process of curriculum development (cited in Elliot et al., 2016). However, recent studies have highlighted the opportunities in the hidden curriculum and the need to recognize and harness it for use in curriculum planning, implementation, and evaluation (Elliot et al., 2016; Hogdal et al., 2021; Sulaimani \& Gut, 2019; Warren et al., 2019; Zorec \& Dusler, 2016). This would entail identifying and describing the hidden curriculum at work in schools. However, much of what is considered in the process of evaluation is the intended curriculum and the "objective" aspects of schooling (Parlett \& Hamilton, 1972) with the hidden curriculum disregarded due to the methods by which evaluation proceeds with (Elliot et al., 2016). As evinced by most studies (Acar, 2012; Bray et al., 2018; Elliot et al., 2016; Hogdal et al., 2021; Mirabueno, 2003; Mossop, et al., 2013; Sambell \& McDowell, 1998; Warren et al., 2019; Winter \& Cotton, 2012) conducted on the hidden curriculum, qualitative methods have been primarily used (Cobanoglu \& Engin Demir, 2014). Despite this presumed significance of the hidden curriculum in student development, studies about these are almost nil in the Philippine context. One of the reasons for this lack is perhaps the absence of concrete methods of understanding and analyzing the hidden curriculum.

This study therefore aimed to determine whether the IEM can be used as a methodology in understanding and analyzing the hidden curriculum and its influences on the character development of pre-elementary students. Character development, as one furthers in age and educational level, is influenced by an increasing complexity of factors and settings. This study, 
thus, focused on the pre-elementary level with their primary environments being the home and the school.

Specifically, this study seeks to answer the following research questions:

- How can the three-step framework of the IEM be used to describe the hidden curriculum among pre-elementary students?

- What are the principles and patterns in the students' character development influenced by the hidden curriculum?

- How does the hidden curriculum reveal the disparities and features in the character development for pre-elementary school students?

\section{LITERATURE REVIEW}

\section{The hidden curriculum}

The hidden curriculum, as coined and used by Philip Jackson in his 1960s pioneering work, refers to the "unpublicised features of school life" (Jackson, 1968, p.17). It has also been called the 'implicit curriculum' or the 'unwritten curriculum,' highlighting how it involves values, expectations, and outcomes or by-products of schooling which are not generally included in the intended curriculum but are learned by students, thus influencing the character and direction of their lives (Eisner, 1985; Goodlad, 1984; King, 1986; Martin, 1976). Due to the latent transmission and reinforcement of attitudes and behaviors inherent in the hidden curriculum, it was perceived as having functional roles in providing the elements of socialization in the maintenance of society or even in becoming oppressive agencies of domination through cultural reproduction (Hlebowitsh, 1994; Vallance, 1973).

Putting these together, Portelli (1993) describes the hidden curriculum to have four major meanings in curriculum discourse: (1) the unofficial expectations (implicit but expected messages); (2) unintended learning outcomes; (3) implicit messages arising from the structure of schooling; and (4) the curriculum as created and interpreted by students.

A more in-depth look at the hidden curriculum in schools may tell a lot about the reasons for inconsistencies between the intended and the learned curriculum. In a classic study on American public schools conducted by Goodlad (1984) with his associates, it was noted how creative thought and critical thinking skills were not really espoused even in subjects where these skills are of prime importance. Along with that, a closer look on the physical environment of the schools lends itself to a critique of how schools do not seem to serve fertile grounds of inspiration in terms of encouraging creativity and wonder through students' aesthetic senses. The instructional methods used by teachers such as lengthy lectures and lack of group collaborative activities reflect how passivity and independence are the much-desired attitudes among students. As such, the perpetuated goals of schools as learning environments and avenues of growth and development are deemed largely inconsistent with what is actually learned by students.

Several studies (Bray et al., 2018; Hogdal et al., 2021; Warren et al., 2019; Zorec \& Dosler, 2016) across different levels and disciplines of education have recognized misalignments between the intended curriculum and the hidden curriculum. This resulted to educational and program goals which are not fully attained as intended. These inconsistencies were brought about by teacher habits and practices (Zorec \& Dosler, 2016); instructional delivery practices, student-teacher interaction, school governance (Hogdal et al., 2021), inherent subject-matter biases (Warren et al. 2019); and wider socio-economic and cultural contexts (Bray et al., 2018). On the contrary, when the hidden curriculum is recognized and identified, research (Elliot et al., 
2016; Lindsay, 2020; Sulaimani \& Gut, 2019) suggests that it can be an effective tool for utilization and integration in curriculum planning. An awareness of the hidden curriculum will help students succeed in different societal and academic contexts.

These circumstances of schooling of which the hidden curriculum is primarily concerned with is indeed crucial if we are to have a more holistic understanding of character development. If one would look at questions of curriculum quality, one should go beyond what is purported to be taught to what is caught by the students during their schooling. To have a full understanding of student experiences through the learned curriculum, the workings of the intended curriculum need to be analyzed side-by-side with an uncovering of the dynamics of the hidden curriculum.

\section{The Illuminative Evaluation Model}

The characteristics of the IEM which makes it fit for a study on the hidden curriculum involve the following: (1) it deals with description and interpretation rather than measurement and prediction, (2) it uses the instructional system and the learning milieu as central concepts, (3) it is appropriate for dealing with questions which lack precision, and (4) it is commonly used in small-scale curriculum projects pertaining to the context of a classroom or classrooms in a school (Lubiano, 2013; Parlett \& Hamilton, 1972). Though used as a model for the purpose of curriculum evaluation, Parlett \& Hamilton (1972) asserts that the IEM is:

Not a standard methodological package but a general research strategy...The choice of research tactics follows not from research doctrine, but from decisions in each case as to the best available techniques: the problem defines the methods used, not vice versa. (p. 17)

Following this precept, the IEM follows three stages. The first stage, Investigate, is more ethnographic in nature in that the researcher familiarizes herself thoroughly with the instructional system and the learning milieu. The instructional system is a catalog description containing the idealized specification of the school's program, while the learning milieu refers to the social-psychological and material environment of the school (Parlett \& Hamilton, 1972). The second step is to Inquire Further, wherein phenomena, occurrences or groups of opinions are selected for intensive inquiry. Emergent issues or themes found to be critical in identifying underlying problems, interrelationships among variables, and invisible realities are given focus with the goal of finding real explanations of issues. The third stage, Explain, consists of interpretation and explanation. From the collected data and information, the researcher then seeks for principles, themes, and patterns which may explain organizational structures, reveal cause-and-effect relationships and situate messages and meanings in a broader explanatory context (Lubiano, 2013).

\section{Character development}

Beyond the development of skills and abilities in academics which teachers are tasked to do, educational experiences provide a lot more to the students. Character education is seen as embedded in this whole process of teaching and learning, from the intended curriculum into actual classroom instruction (Suhartini et al., 2019) leading to the learned curriculum.

Moreover, the 21st century has seen an increased effort to enhance the development of values and character in schools in an attempt to address national issues concerning the youth and the future. This is in response to the alarming and disturbing levels of deviant behavior among students influencing their personalities and identities (Berges-Puyó, 2020; Suhartini et al., 2019). Concepts such as positive education, values education, character education, or 
resilience learning are being used in countries around the world with the purpose of developing students' character and values (Berges-Puyó, 2020).

Character development, which is heavily influenced by social factors, is a crucial aspect of student development. Due to its nature, character education is primarily induced through conditioning students into certain socializing skills, behaviors, and attitudes which schools find as essential conventions needed to sustain collective life. Values and character development is considered as a transmission of dominant values involving a multifaceted process of socialization in schools (Margolis, 2001; Zajda, 2014).

In the case of private sectarian schools, central to the development of students' character is spiritual development as it relates to the principles of their religion. The ways by which character is built through religious school culture is found to be predictive for student religious character (Marini et al., 2018). This is facilitated through the presence of worship facilities, religious ceremonies, and religious symbols which promote the effectiveness of character building in religious school culture.

Berges-Puyó (2020) advocates for an approach on values and character development that is holistic involving the following elements: family, government, school administration, teachers, and students. The family plays a firsthand role in transmitting values which powerfully influences children's character. Secondly, governments influence school culture through their educational models that condition the principles, values, vision, and expectations of actors within schools. The school administration, on the other hand, is a crucial factor influencing teacher performance, retention, and resignation. The environment and support provided by administrators are reflected in the performance of the teachers. Teachers then are the major players in character development as they not only teach content, but also become the conduits and role models of good character for the students.

Character is reflected through attitudes, behavior, and habits conditioned by the surrounding context. Suhartini et al., (2019) further notes that the social construction of student behavior occurs through a dialectical process comprising three simultaneous moments. First is externalization which involves an adaptation and habituation process where activities and ceremonies are carried out. Objectivation refers to institutionalization and legitimacy, where the intersubjective world of students is activated through social interaction and participation. Lastly, internalization involves identification within the social institution whose identity becomes part of the student's character.

The process of character development involves the cultivation of three critical aspects of a person, namely, the cognitive, the emotional, and the behavioral side (Windmiller et al., 1980). Examining character development should thus be done in the context of a holistic approach which values all student's learning factors. Furthermore, education should be a holistic mechanism that values the cognitive, emotional, and social aspects of learning (cited in BergesPuyó, 2020, p.3).

It is in these light that the hidden curriculum plays a critical role in forming the values, beliefs, and behavior of the students through its socializing and ideological functions in the school. The formative years of a child, namely, the pre-elementary years are especially crucial as these are the years where children are ushered into schooling. It is in these years of early childhood where important cognitive, social, and emotional skills are primarily developed as conditioned by the stimulus within the child's environment (cited in Evans et al., 2018).

Hence, in the study of character development among students as it relates to the hidden curriculum, it is necessary that methods used would consider the following: (1) real school 
settings wherein the study would be conducted, (2) multiplicity of sources to serve as evidence in identifying the components of the hidden curriculum, (3) the educational processes which provide meanings to the how's and why's of the hidden curriculum, (4) the absence of a predetermined thesis in order to come up with emergent themes and synthesis about it, and (5) a comprehensive survey of the different actors, i.e., teachers, students, parents, administrators, etc., who play a role in its formulation and sustenance (Cobanoglu \& Engin Demir, 2014).

This paper sought to determine whether the IEM with its three-step framework - (1) Investigate, (2) Inquire Further, (3) Explain - can be used in understanding and analyzing the hidden curriculum and its influences on the character development of pre-elementary students.

In order to get an accurate and more complete picture of the curriculum as it was implemented, evaluation should proceed beyond the intended to that of the learned curriculum. It is in the spaces and gaps between these two that the hidden curriculum primarily functions. An understanding of the dynamics of these would require a comprehensive description of the learning milieu through which the details of the implementation process occur. The model espouses the collection of data from four main methods: observations, interviews, questionnaires and tests, and documentary and background sources (Parlett \& Hamilton, 1972). As a study on the hidden curriculum, the last stage of the evaluation is on the interpretation and analysis of the reasons for, and responses to, the deviations and unintended outcomes vis-a-vis the intended curriculum. This results to the formation of general principles and patterns describing the hidden curriculum and its influences on students' character development.

Figure 1 is derived from the explication model to describe the framework employed in this research study on the influences of the hidden curriculum on character development using the IEM:

Figure 1. The Illuminative Evaluation Model as derived from the Explication Model
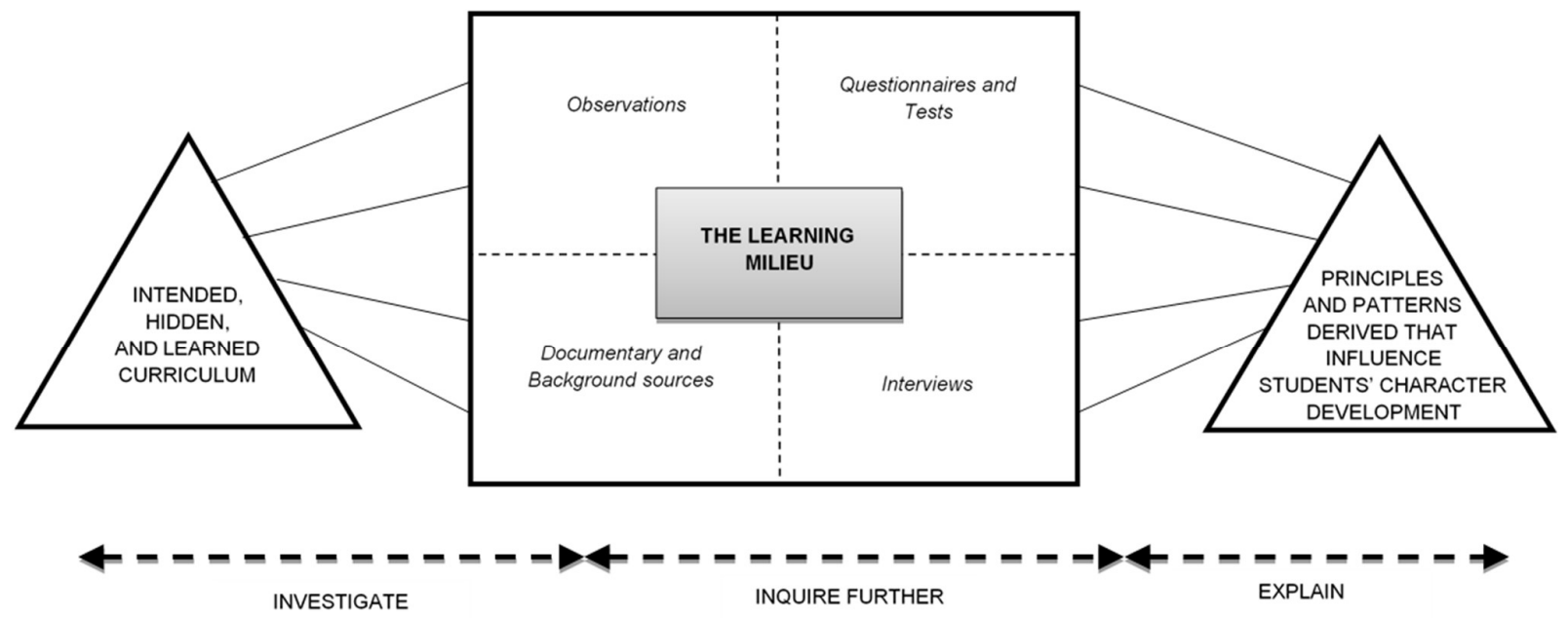


\section{Research design}

\section{METHODS}

The research employed content analysis as its primary method and design. This is to formulate themes that describe the hidden curriculum from the collection of data espoused by IEM. Content analysis facilitates the study of human behavior in an indirect way revealing conscious or unconscious beliefs, attitudes, values and ideas of persons or groups (Fraenkel \& Wallen, 2009). The development of themes from the research is emergent as prescribed by the IEM.

The aim of the research is to evaluate the curriculum with an emphasis on the learning milieu or the social-psychological and material environment of the school (Parlett \& Hamilton, 1972). The goal is to examine the implementation of the curriculum within the learning milieu in order to illuminate the dynamics of the hidden curriculum.

The focus of analysis are the patterns of behavior reflected by the actors within the school community. The data that informs this content analysis are curriculum documents, observed classroom practices, and responses to questionnaires, interviews, and focus group discussions. The research used purposive sampling of pre-elementary students in a private Christian school in San Juan City, Philippines.

\section{Data collection}

Data was derived from the intended curriculum and the implemented curriculum. Using the three-step framework of the IEM, the intended curriculum was examined in Stage 1 Investigate through document review of formal curriculum texts. The purpose was to describe the instructional system containing the idealized specification of the educational program (Parlett \& Hamilton, 1972), particularly the student characteristics targeted to be developed through the intended curriculum. Moreover, to understand the contexts of student development among the pre-elementary students, data was gathered from the implemented curriculum. These include daily unstructured observations in the classrooms and pertinent parts of the school, and informal interviews with teachers and staff.

For Stage 2 Inquire Further, data sources included pertinent school documents related to identified issues from Stage 1 on deviations and unintended outcomes. In addition, data was collected on curriculum implementation through focused and structured classroom observations, and structured interviews with select participants. Emerging issues were validated through surveys given to parents.

In Stage 3 Explain, data sources included separate focus group discussions with the class advisers and the school administrators. This is to further validate initial findings and to formulate principles and patterns in students' character development that are influenced by the hidden curriculum.

Thus, content analysis was primarily used to organize the large amount of data (Fraenkel \& Wallen, 2009) derived from the four main methods of data collection stipulated in the IEM which are observation, document review, questionnaires/surveys, and interviews (Parlett \& Hamilton, 1972).

\section{Research procedures}

This study is a descriptive research which seeks to provide a complete picture of the interaction of various factors which come to determine the school's hidden curriculum. The study employed naturalistic methods, wherein the researcher was a participant-observer in the school environment, experiencing what it meant to be a teacher and/or a student.

The research proceeded for approximately four months in a private Christian school in San Juan City whose main thrust is to provide quality education to students in a Christian 
environment while striving to teach students to look at the world with a Biblical perspective. The school studied has as its primary objective the promotion of Christian education which attests to the highest standards of morality, Christian behavior and academic excellence as conditioned by a Christian environment. The processes and contexts by which this objective is sought to be achieved are carefully looked into with the aim of understanding the hidden curriculum through its professed goals and environment.

The school has three preschool levels with single sections each: Pre-Kinder 1 has seven students, Pre-Kinder 2 has eight, while Kindergarten has ten, totaling 25. Total population sample of the pre-elementary level of the school was employed in order to examine key characteristics of each differing level, and at the same time to compare the reinforcement and progression of initiatives on character development across increasing preschool levels.

The time period involved was the start of classes for the school year, thus involving adjustment periods especially for the Pre-Kinder 1 students. Due to the overlapping schedules of the pre-elementary classes, the researcher did alternate observations among the three classes.

This research focused on one school only as the model is commonly used in small-scale curriculum projects pertaining to specific classroom contexts (cited in Lubiano, 2013). The selection of the sample and the site were found to be appropriate for this study since its main thrust is to focus and conduct in-depth investigations in a specific context, rather than generalizability to other settings. The focus was on the particular set of characteristics that were developed in students in their pre-elementary years since these constitute the critical stage of learning wherein a student is ushered into schooling, and therefore into its formal and hidden curricula (Bronfenbrenner, 1994; King, 1986).

\section{Data analysis}

The study followed the model's three-step framework: (1) Investigate, (2) Inquire Further, and (3) Explain, as well as the model's recommended research instruments.

In Stage 1, the instructional system was understood and described through initial document analysis of the school manual, (containing the policies, vision, mission, philosophy, goals, etc.), intended curriculum for kindergarten, the Department of Education's learning standards for kindergarten, pre-elementary textbooks, teachers' lesson plans and unit plans, and students' and teachers' profiles. Afterwards, the learning milieu was examined through daily classroom observations; interviews with key people from the administration, preelementary teachers, and select school personnel; and further document analysis of relevant documents. The goal of examining the learning milieu was to identify key characteristics that were targeted to be developed among the students through the intended curriculum, and the deviations that occurred during its implementation.

For Stage 2, selected concerns and deviations found pertinent to an understanding of the influences of the hidden curriculum to character development were identified. With the aim of progressively focusing upon these issues, surveys were distributed to parents, structured daily observations were conducted, and a focus group discussion was held with the three class advisers.

Lastly, Stage 3 involved the validation of initial findings with the administration through another focus group discussion.

The qualitative information gathered through document analysis, interviews, focus group discussions, and observations, were analyzed through the identification of constructs, categories and themes (CCT) which emerged. From the surveys, coding and descriptive statistics 
were used to supplement initial data. Finally, data was organized into overarching themes which describe the influences of the hidden curriculum on students' character development.

\section{RESULTS AND DISCUSSION}

\section{Describing the hidden curriculum through the three-step framework of the IEM} Student characteristics targeted to be developed through the intended curriculum

During Stage 1 Investigate, the instructional system and the learning milieu were explored resulting in the identification of these five key traits: (1) godly leadership, (2) Lordship of Christ, (3) excellent Christian lifestyle, (4) lives of legacy, and (5) global competence (Gunio \& Fajardo, 2018). As a Christian school, the primacy of putting Christ as central to the students' lives and encouraging them to take the lead in influencing other people for evangelistic purposes and for humanitarian causes is part of its ulterior goals. At the same time, excellence in both the academic and spiritual aspects is envisioned among its students to make them competent wherever they eventually choose to be and in whatever field they may take.

\section{Deviations and unintended outcomes for progressive focusing}

In Stage 2 Inquire Further, progressive focusing was conducted on the following concerns: (1) repetitive cases of disobedience; (2) self-centred leadership; (3) prejudiced treatment of, and attitude towards classmates; (4) lack of interest and lazy disposition towards studying; (5) sexually-related cases; (6) incongruent teaching philosophies; (7) inconsistency in implementation of language policies; and, (8) administrative and management policy concerns (Gunio \& Fajardo, 2018).

\section{Aspects of the hidden curriculum among pre-elementary students}

The discussion in Stage 3 Explain focused on five distinct aspects of the hidden curriculum that emerged, namely: (1) the inculcation of school values and principles, (2) approaches to character development, (3) development of readiness for formal schooling, (4) functions of the physical environment, and (5) managerial and policy concerns (Gunio \& Fajardo, 2018).

General principles and patterns in students' character development influenced by the hidden curriculum

The inculcation of school values and principles proceeded through the hidden curriculum in the form of (a) formal ceremonies such as their weekly mini-church services and flag ceremonies which transmit values of godliness and excellence, spiritual and academic integration, the school as a family, and leadership; (b) class routines centered on specific class rules which enforce the importance of praying at all times, following authority, and individual achievement; and (c) the memorization of Scripture verses in imparting the Bible as the source of truth, and the role of rote memorization in breeding eventual life application of these verses. The inculcation of principles demonstrated reflects the dialectical process of externalization, objectivation and internalization (Suhartini et al., 2019) which leads to the social construction of student behavior.

As a Christian school, character development is explicit in the school's intended curriculum. Moreover, research provides empirical character education implementation strategies (Berkowitz, 2011). However, in the case of the study, approaches to character development are not indicated in the intended curriculum and are rather employed by the teachers based on factors such as personality, autonomy, discretion, and belief system. These strategies condition culture and norms which yield unofficial expectations or unintended learning outcomes which constitute the hidden curriculum (Portelli, 1993). These approaches to character development are thus subsumed in the hidden curriculum and involve the 
following: (a) social conventions conditioned through moral principles, (b) use of dialogue and reflection, (c) system of accountability, (d) role playing/role modeling, (e) publicly addressing negative behavior, (f) reference to authority figure/use of fear, $(g)$ direct teaching/practice of behavioral skills, (h) system of rewards and punishment, (i) teacher conference, (j) parentteacher conference, and $(k)$ positive confession of behavior. Most of these approaches are parallel with some of the general techniques supporting character development which are subsumed under the concept of prosocial guidance (cited in Priest, 2007). Other approaches, however, such as the use of rewards and punishment, have been regarded as unfitting for developmental discipline due to its inability to encourage discipline based on internal values and intrinsic motivation (Priest, 2007).

Another aspect of the hidden curriculum in the school involves the activities which influence character development by training students to develop readiness for formal schooling. These activities were accomplished through (a) training for independence through classroom routines, (b) providing constant practice on writing skills, (c) habituating them into an increased volume of subjects as compared to the typical load of pre-elementary students, and (d) orienting children into maturing roles and activities.

Aside from these, the hidden curriculum also played a role through the physical environment of the pre-elementary rooms and of the very school itself (Margolis, 2001) such that it conditioned them into (a) being more independent, (b) becoming more aware of their behavior due to close monitoring, (c) being disciplined within the confines of the classroom, and (d) being appreciative of a rather meager representation of nature within the school facilities.

Lastly, the hidden curriculum's impact existed beyond concerns within the classroom doors and into the more personal nature of (a) teacher personality factors, (b) teacher and administration connections, and (c) the pervading conception of teaching as a ministry leading to low compensation and teacher satisfaction. These were crucial elements influencing students' character development (Berges-Puyó, 2020) from a more organizational perspective as they impact teachers' behavior and attitudes.

\section{The disparities and features in character development revealed in the hidden curriculum}

Aside from these findings derived from the research problems, it was realized that the focus of the explication process (Ornstein \& Hunkins, 1993) - from which the IEM is derived - in exposing the disparities between goals and outcomes served to limit the process. Part of the findings of this research study is concerned with the methodology used in uncovering the dynamics of the hidden curriculum. The focus on deviations or inconsistencies made it challenging for the researcher in a context wherein positive results were being gathered initially. As observed, the hidden curriculum, in terms of the school environment and the approaches to behavior correction worked accordingly to positively develop the character of the students. As such, conceiving the hidden curriculum merely in the context of deviations and inconsistencies did not work to illuminate it but rather to limit it.

Based on the study, it is crucial that an understanding of the dynamics of the hidden curriculum be represented both in spaces pertaining to deviations or inconsistencies, and just the same through the reinforcement of school goals as evident through recurring trends or incidents. The first stage of investigation should take into account both the ways by which the instructional system worked and did not work in the context of the learning milieu. Incidents which produce similar effects also have to be considered to highlight the significant features of the program, for the hidden curriculum can both serve to fulfill or to deviate from the instructional system. 
Hence, in the study of the hidden curriculum, these two aspects - disparities and features - should be taken into account so as to present a more complete picture of how the intended curriculum interplays with the hidden curriculum to form the learned curriculum.

\section{CONCLUSION}

In summary, three conclusions have been derived from this study. First, the IEM, as a tool or method, was indeed effective in determining the influences of the hidden curriculum on students' character development. The three-stage framework of the model helped to accomplish the process of illumination by bringing out the realities and complexities of the interaction between the intended and the learned curriculum, and the gaps and spaces in the interplay of the instructional system and the learning milieu; thus, the dynamics of the hidden curriculum.

Secondly, the hidden curriculum involves the processes, settings, and situations inherent in the learning milieu, thus, conditioning the learned curriculum - which are not explicitly stated in the intended curriculum but influence the character and experience of the members of the school community, whether intentionally or unintentionally. The intended curriculum interplays with the hidden curriculum through the contexts and conditions during program implementation. This allows students to internalize certain modes of behavior, perspectives, and attitudes which prove foundational to the development of their character as they eventually move on to higher levels in their schooling. The dynamics of the hidden curriculum may work intentionally in the accomplishment of the school's curricular goals, or rather unintentionally in the frustration of these goals.

Lastly, in the study of the hidden curriculum, the IEM should take into account not only the disparities, but also the features evident between the school goals and the outcomes. In the course of the study, the researcher found it necessary that apart from deviations or disparities, the school's features be examined as well. This is evident in common incidents or recurring trends which lead to consistencies between school goals and outcomes.

\section{Corrigendum}

The following post-publication correction has been made to this article: A reference, "Gunio \& Fajardo, 2018", has been added in page 202 in three different paragraphs, and this reference has been included in the References list in page 205 as follows: Gunio, M. J. D., \& Fajardo, A. C. (2018). Evaluating the Hidden Curriculum and its Impact on the Character Development of Preschool Students. Asia Pacific Journal on Curriculum Studies, 1(1), 20-25. https://doi.org/10.46303/apjcs.2018.4

\section{REFERENCES}

Acar, E. (2012). Hidden curriculum contributing to social production-reproduction in a math classroom. International Online Journal of Educational Sciences, 4(1), 19-30.

Berges-Puyó, G. (2020). A value and character educational model: Repercussions for students, teachers, and families. Journal of Culture and Values in Education. https://doi.org/10.46303/jcve.2020.7

Berkowitz, M.W. (2011). What works in values education? International Journal of Educational Research, 50(3), 153-158. https://doi.org/10.1016/j.ijer.2011.07.003

Bray, M., Kobakhidze, M.N., Zhang, W., \& Liu, J. (2018). The hidden curriculum in a hidden marketplace: Relationships and values in Cambodia's shadow education system. Journal of Curriculum Studies 50(4), 435-455. https://doi.org/10.1080/00220272.2018.1461932 
Bronfenbrenner, U. (1994). Ecological models of human development. International Encyclopedia of Education, 3(2), 37-43.

Cobanoglu, R. \& Engin Demir, C. (2014). The visible side of the hidden curriculum. Elementary Education Online, 13(3), 776-786.

Eisner, E.W. (1985). The educational imagination: On the design and evaluation of school programs (2nd ed.). Macmillan.

Elliot, D.L., Baumfield, V., Reid, K., Makara, K.A. (2016). Hidden treasure: successful international doctoral students who found and harnessed the hidden curriculum. Oxford Review of Education, 42(6), 733-748. http://dx.doi.org/10.1080/03054985.2016.1229664

Evans, K., Russell, W.B., Furgione, B. \& Sheridan, A. (2018). Won't you be my neighbor? A study of familial perceptions of character education in PBS media programming in the United States? Journal of Culture and Values in Education, 1(2), 1-22. https://doi.org/10.46303/jcve.01.02.1

Fraenkel, J.R. \& Wallen, N.E., (2009). How to design and evaluate research in education. $7^{\text {th }}$ Edition). McGraw-Hill Higher Education.

Glatthorn, A. A., Boschee, F., \& Whitehead, B. M. (2009). Curriculum leadership: Strategies for development and implementation. SAGE Publications, Inc.

Goodlad, J. (1984). A place called school: Prospects for the future. McGraw-Hill Book.

Halpern, 2018. The gears of the hidden curriculum revisited. Journal of Curriculum Theorizing, 33(1), 40-44.

Gunio, M. J. D., \& Fajardo, A. C. (2018). Evaluating the Hidden Curriculum and its Impact on the Character Development of Preschool Students. Asia Pacific Journal on Curriculum Studies, 1(1), 20-25. https://doi.org/10.46303/apjcs.2018.4

Hogdal, C., Rasche, A., Schoeneborn, D., \& Scotti, L. (2021). Exploring student perceptions of the hidden curriculum in Responsible Management Education. Journal of Business Ethics, 168, 173-193. https://doi.org/10.1007/s10551-019-04221-9

Hlebowitsh, P. S. (1994). The forgotten hidden curriculum. Journal of Curriculum and Supervision, 9(4), 339-349. https://eric.ed.gov/?id=EJ486341

Jackson, P. W. (1968). Life in classrooms. Holt, Reinhart, and Winston.

King, S. E. (1986). Are you doing inquiry along these lines? Inquiry into the hidden curriculum. Journal of Curriculum and Supervision, 2(1), 82-90. http://www.ascd.org/ASCD/pdf/journals/jcs/jcs 1986fall king.pdf

Lindsay, J. (2020). Decolonizing the curriculum. Springer Nature. https://doi.org/10.1007/s12129-020-09899-2

Lubiano, A. (2013). Instructional evaluation model for an elementary mathematics program. [Unpublished master's thesis]. University of the Philippines, Diliman.

Madaus, G., Scriven, M., \& Stufflebeam, D. (Eds.). (1983). Evaluation models: Viewpoints on educational and human services evaluation. Kluwer-Nijhoff.

Margolis, E. (2001). The hidden curriculum in higher education. Routledge.

Marini, A., Safiri, D., \& Muda, I. (2018). Managing school based on character building in the context of religious school culture (Case in Indonesia). Journal of Social Studies Education Research, 9 (4), 274-294. https://isser.org/index.php/isser/article/view/345/337

Martin, J. R. (1976). What should we do with a hidden curriculum when we find one? Curriculum Inquiry 6(2), 135-151. https://doi.org/10.1080/03626784.1976.11075525 
Mirabueno, B. (2003). The hidden curriculum in teaching social studies II in a public high school. [Unpublished thesis]. UP Diliman, Quezon City.

Mossop, L., Dennick, R., Hammond, R., \& Robbe, I. (2013). Analysing the hidden curriculum: Use of a cultural web. Medical Education, 47(2), 134-143. https://doi.org/10.1111/medu.12072

Ornstein, A., \& Hunkins, F. (1993). Curriculum: Foundations, principles, and issues. Allyn and Bacon.

Parlett, M. \& Hamilton, D. (1972). Evaluation as illumination: A new approach to the study of innovatory programs. Education Resources Information Center. https://eric.ed.gov/?id=ED167634

Portelli, J.P. (1993). Exposing the hidden curriculum. Journal of Curriculum Studies, 25(4), 343 358. https://doi.org.ezproxy.upd.edu.ph/10.1080/0022027930250404

Priest, C. (2007). Incorporating character education into the early childhood degree program: The need, and one department's response. Journal of Early Childhood Teacher Education, 28(2), 153-161. https://doi.org/10.1080/10901020701366723

Sambell, K., \& McDowell, L. (1998). The construction of the hidden curriculum: Messages and meanings in the assessment of student learning. Assessment and Evaluation in Higher Education, 23(4), 391-403.

Suhartini, S., Sekarningrum, B., Sulaeman, M.M. \& Gunawan, W. (2019). Social construction of student behavior through character education based on local wisdom. Journal of Social Studies Education Research, 10 (3), 276-291.

https://jsser.org/index.php/isser/article/view/1075/398

Sulaimani, M.F., \& Gut, D.M. (2019). Hidden curriculum in a special education context: The case of individuals with autism. Journal of Educational Research and Practice 9(1), 3039. https://doi.org/10.5590/JERAP.2019.09.1.03

Tallerico, M. (2012). Leading curriculum improvement. Rowman \& Littlefield Education. Vallance, E. (1973). Hiding the hidden curriculum: An interpretation of the language of justification in nineteenth-century educational reforms. Curriculum Theory Network, 4(1), 5-21. https://www.jstor.org/stable/1179123

Warren, K., Mitten, D., D'Amore, C., \& Lotz, E., (2019). The gendered hidden curriculum of adventure education. Journal of Experiential Education, 42(2), 140-154. DOI: $10.1177 / 1053825918813398$

Windmiller, M., Lambert, N., \& Turiel, E. (1980). Moral development and socialization. Allyn and Bacon.

Winter, J., \& Cotton, D. (2012). Making the hidden curriculum visible: Sustainability literacy in higher education. Environmental Education Research, 783-796.

Zajda, J. (2014). Values education. In D. Phillips (Ed.), Encyclopedia of educational theory and philosophy, 835-838. SAGE.

Zorec, M.B., \& Dosler, A.J., (2016). Rethinking the hidden curriculum: daily routine in Slovene preschools. European Early Childhood Education Research Journal, 24(1), 103-114. http://dx.doi.org/10.1080/1350293X.2015.1120523 